Pure Appl. Chem., Vol. 73, No. 3, pp. 449-453, 2001.

(C) 2001 IUPAC

\title{
Long-distance charge transport through DNA. An extended hopping model ${ }^{\star}$
}

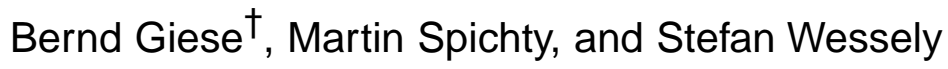 \\ Department of Chemistry, University of Basel, St. Johanns Ring 19, CH-4056 \\ Basel, Switzerland
}

\begin{abstract}
Long-distance transfer of a positive charge through DNA can be described by a hopping model. In double strands where the (A:T $)_{n}$ bridges between the guanines are short $(n \geq 3)$, the charge hops only between guanines, and each hopping step depends strongly upon the guanine to guanine distances. In strands where the $(\mathrm{A}: \mathrm{T})_{n}$ sequences between the guanines are rather long $(n \geq 4)$, also the adenines act as charge carriers. To predict the yields of the $\mathrm{H}_{2} \mathrm{O}$-trapping products one has to take into account not only the charge-transfer rates but also the rates of $\mathrm{H}_{2} \mathrm{O}$-trapping reactions.
\end{abstract}

In the 1990s, the question of long-distance electron transfer through DNA raised a controversial discussion [1]. We entered this area three years ago by studying radical-induced DNA strand cleavage reactions. Our experiments showed that photolysis of a 4'-acylated nucleoside in the DNA double strand $\mathbf{1}$ yields radical cation 2 that selectively oxidizes guanine $(G)$ and forms a guanine radical cation $\left(\mathrm{G}^{*+}\right)$ in 3 (Fig. 1) [2].

This reaction sequence led to an assay that made it possible to follow the charge migration through DNA by trapping of the positive charge at the heterocyclic base [3]. In order to understand the experimental results, we suggested in 1998 a hopping mechanism [3] for long-distance charge transport through DNA, which is based on the theoretical model of Jortner [4]. A similar hopping mechanism, which is slightly different in the details, was also suggested by Schuster [5], and today there is a con-

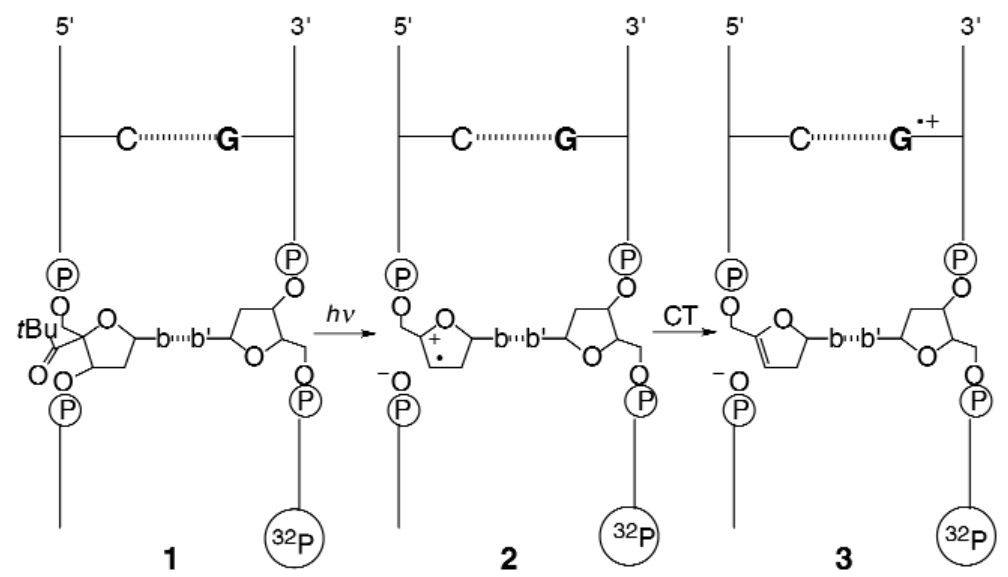

Fig. 1 Assay for the charge injection into a guanine $(\mathrm{G})$.

*Lecture presented at the XVIII ${ }^{\text {th }}$ IUPAC Symposium on Photochemistry, Dresden, Germany, 22-27 July 2000. Other presentations are published in this issue, pp. 395-548.

†Corresponding author 


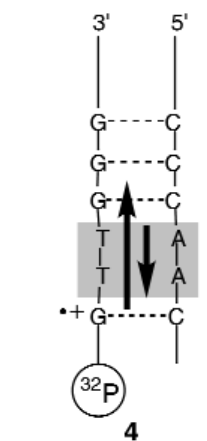

$P_{G G G}: 90 \%$

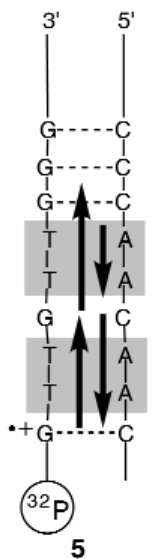

$73 \%$

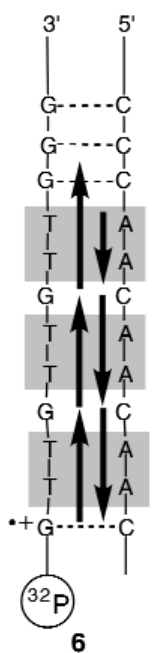

$52 \%$

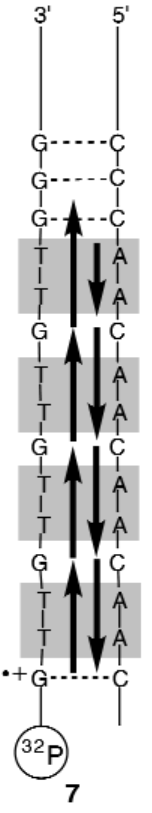

$43 \%$

Fig. 2 Yield of $\mathrm{H}_{2} \mathrm{O}$-trapping products at the GGG sequence $\left(\mathrm{P}_{\mathrm{GGG}}\right)$ in long-distance charge transfer by a hopping between guanines $(\mathrm{G})$.

sensus that long-distance charge transport through DNA occurs by a multistep hopping process [6]. Out of the four natural heterocyclic bases guanine $(G)$ has the lowest ionization potential [7], therefore $G$ is the preferred carrier of the positive charge. Thus, in double strands 4-7 of Fig. 2 the positive charge hops between the guanines to the GGG unit, which has an even lower redox potential than a single G. Trapping of the guanosine radical cation $\left(\mathrm{G}^{*+}\right)$ leads to products $\mathrm{P}_{\mathrm{G}}$ and $\mathrm{P}_{\mathrm{GGG}}$ that are separated and analyzed quantitatively by gel electrophoresis.

This hopping model implies that the electron transfer from a $\mathrm{G}$ to $\mathrm{a} \mathrm{G}^{\bullet+}$ is faster than the trapping reaction by $\mathrm{H}_{2} \mathrm{O}$ so that the charge should be partly distributed over the guanines before it is trapped [8]. Therefore, the yields of products $\mathrm{P}_{\mathrm{G}}$ decrease only slightly from $\mathrm{P}_{\mathrm{G} 1}$ to $\mathrm{P}_{\mathrm{G} 4}$, although the distance to the charge donor $\mathrm{G}_{1}{ }^{\circ+}$ increases by $10 \AA$ per each hopping step (Fig. 3).

This slow decrease of the product yields must not be mixed up with a weak distance influence on the charge-transfer rate. It is the ratio between the charge transfer and the $\mathrm{H}_{2} \mathrm{O}$-trapping rates that governs the product ratios (Fig. 4). We have quantitatively described this situation using the Curtin-Hammett principle [10]. The product ratio decreases only slightly as long as the $\mathrm{H}_{2} \mathrm{O}$ reaction is slower than the charge-transfer steps.

Figure 5 shows how the charge migration from $\mathrm{G}_{1}$ via $\mathrm{G}_{2}, \mathrm{G}_{3}, \mathrm{G}_{4}$ to the GGG unit precedes the product formation.

Despite this weak distance influence on the product formation, the influence of the distance on the charge-transfer rate $k_{\mathrm{CT}}$ of each hopping step is large, and the $\beta$-value is about $0.7 \AA^{-1}$ (Fig. 6) $[3,9]$.

Thus, the electron-transfer rate between $\mathrm{G}^{\circ+}$ and $\mathrm{G}$ over an $(\mathrm{A}: \mathrm{T})_{n}$ bridge dramatically decreases with $n$ until one reaches the situation in which the endothermic oxidation of the adjoining adenine (A) by $\mathrm{G}^{\cdot+}$ is as fast as the oxidation of a distant $\mathrm{G}$ [10]. Using a buffer at $\mathrm{pH}=7$, this seems to be the case if the number of A:T base pairs $n$ of the $(\mathrm{A}: \mathrm{T})_{n}$ bridge is larger than 3 where the charge-transfer rate between the guanines is smaller than $10^{5} \mathrm{~s}^{-1}$. As shown in Fig. 7, in these strands also adenines (A) become charge carriers [10]. Once A is oxidized, the charge migrates in fast hopping steps between the 


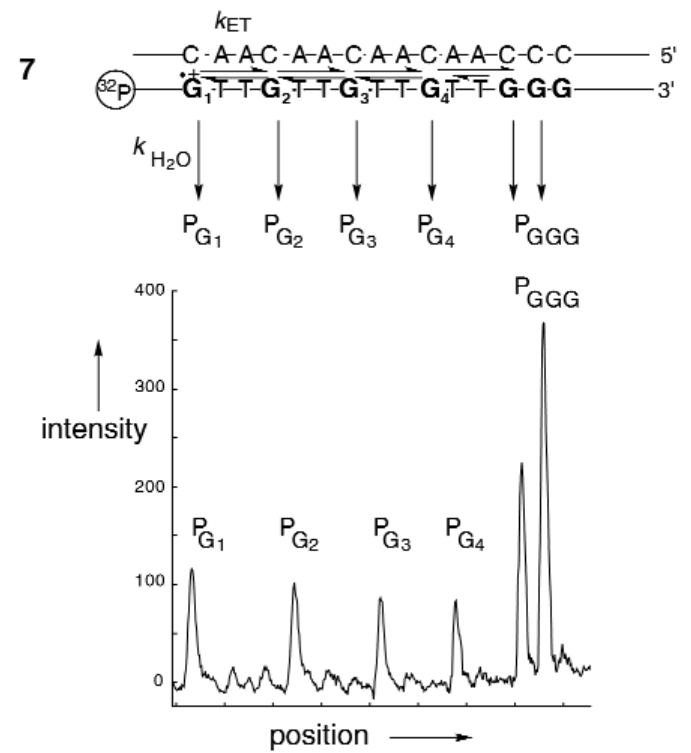

Fig. 3 Product yields $\mathrm{P}_{\mathrm{G}}$ and $\mathrm{P}_{\mathrm{GGG}}$ formed by trapping of the guanosine radical cation $\left(\mathrm{G}^{*+}\right)$ by $\mathrm{H}_{2} \mathrm{O}$ during charge transfer through DNA double strand 7. The positive charge is injected into $G_{1}$ and migrates via $G_{2}, G_{3}$, and $\mathrm{G}_{4}$ to the GGG unit.

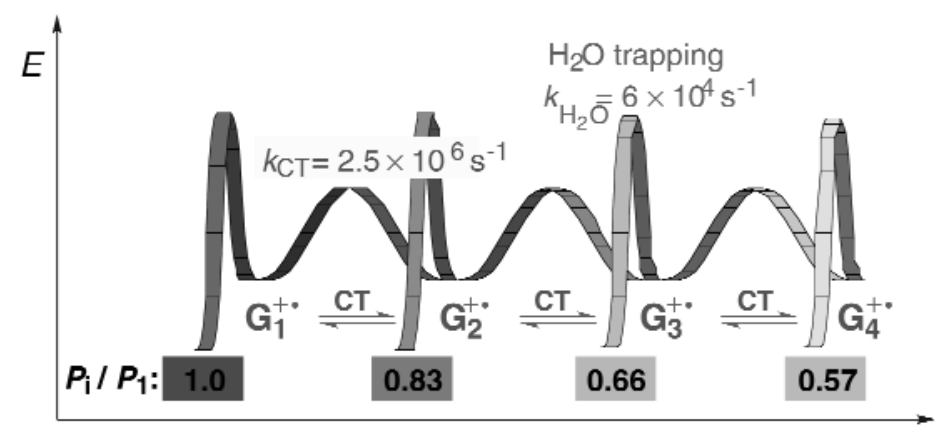

Fig. 4 Reaction profile diagram for the charge transfer and $\mathrm{H}_{2} \mathrm{O}$-trapping of the guanines $\mathrm{G}_{1}$ to $\mathrm{G}_{4}$ of double strand 7 at $\mathrm{pH}=7$.

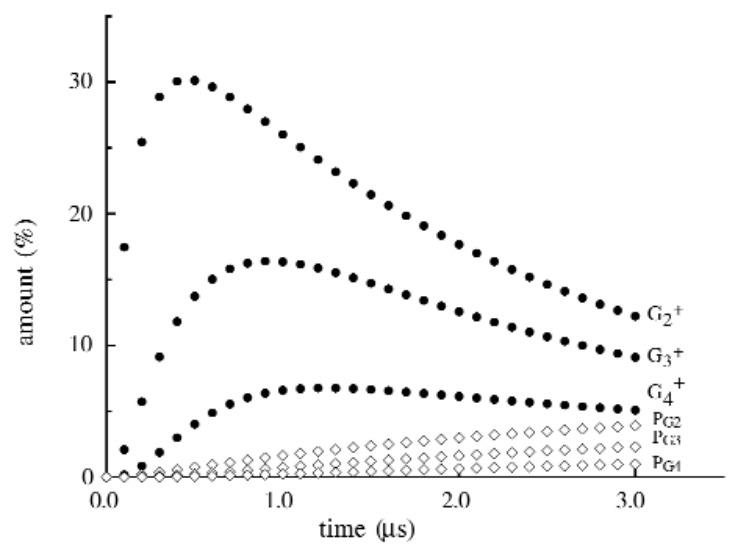

Fig. 5 Calculated charges at $\mathrm{G}_{2}{ }^{\bullet+}, \mathrm{G}_{3}{ }^{{ }^{+}}, \mathrm{G}_{4}{ }^{\bullet+}(\bullet)$, and $\mathrm{H}_{2} \mathrm{O}$-trapping products $\mathrm{P}_{\mathrm{G} 2}, \mathrm{P}_{\mathrm{G} 3}$, and $\mathrm{P}_{\mathrm{G} 4}(\diamond)$ at the positions $\mathrm{G}_{2}, \mathrm{G}_{3}$, and $\mathrm{G}_{4}$, respectively, during charge transfer through double strand 7 at $\mathrm{pH}=7$.

(C) 2001 IUPAC, Pure and Applied Chemistry 73, 449-453 


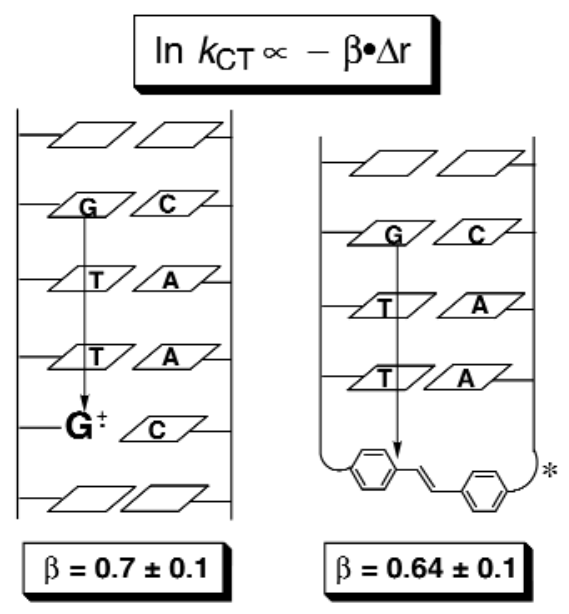

Fig. 6 Experimentally determined $\beta$-values using the assays of Giese [3] or Lewis and Wasielewski [9].

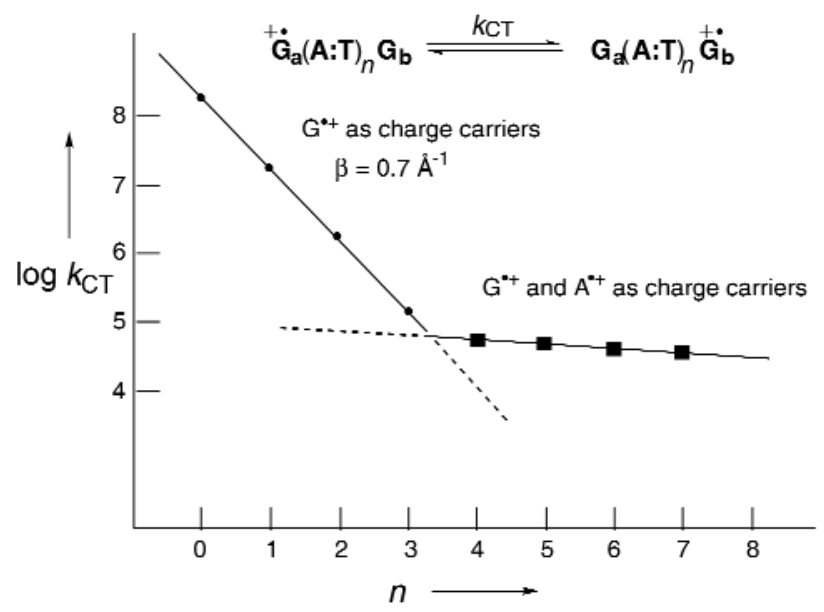

Fig. 7 Dependence of the charge-transfer rate on the number $n$ of A:T base pairs between $\mathrm{G}_{\mathrm{a}}$ and $\mathrm{G}_{\mathrm{b}}$ in DNA double strands at $\mathrm{pH}=7$.

adjoining adenines until it reaches a $\mathrm{G}$, so that the overall charge-transfer rate decreases only slowly with a further elongation of the (A:T) ${ }_{n}$ bridge.

In conclusion, the yields of the trapping products $\mathrm{P}_{\mathrm{G}}$ depend not only upon the charge transfer but also on the $\mathrm{H}_{2} \mathrm{O}$-trapping rates. In DNA double strands, where the $\mathrm{H}_{2} \mathrm{O}$-trapping reaction is very slow and the number of adjoining A:T base pairs is large, guanines and adenines are the carriers of the positive charge, and only a small distance influence on the ratios of products $\mathrm{P}_{\mathrm{G}}$ will be observed. However, if the $\mathrm{H}_{2} \mathrm{O}$-trapping rate is very fast and the number of adjoining A:T base pairs is small into $\mathrm{G}$, only guanines can act as the charge carriers, and the distance influence on the product ratios will be large. In between these two extremes, a complex situation arises. According to the Curtin-Hammett principle, the product ratios can be predicted using the known charge transfer rate constants [11], a $\beta$-value of 0.7 $\AA^{-1}$, and a kinetic model that treats the long-range charge transfer by a hopping mechanism between the guanines for short A:T sequences, or guanines and adenines for long A:T sequences [10]. 


\section{ACKNOWLEDGMENTS}

This work was supported by the Swiss National Science Foundation and the Volkswagen Foundation.

\section{REFERENCES}

1. Commentaries on hole transfer in DNA: a) E. K. Wilson. Chem. Eng. News 77(34), 43 (1999); b) M. Ratner. Nature 397, 480 (1999); c) M. W. Grinstaff. Angew. Chem. Int. Ed. 38, 3629 (1999).

2. E. Meggers, D. Kusch, M. Spichty, U. Wille, B. Giese. Angew. Chem. Int. Ed. 37, 459 (1998); E. Meggers, A. Dussy, T. Schäfer, B. Giese. Chem. Eur. J. 6, 485 (2000).

3. E. Meggers, M. E. Michel-Beyerle, B. Giese. J. Am. Chem. Soc. 120, 12950 (1998).

4. a) J. Jortner, M. Bixon, T. Langenbacher, M. E. Michel-Beyerle. Proc. Natl. Acad. Sci. USA 95, 12759 (1998); b) B. Giese, S. Wessely, M. Spormann, U. Lindemann, E. Meggers, M. E. MichelBeyerle. Angew. Chem. Int. Ed. 38, 996 (1999); c) M. Bixon, B. Giese, S. Wessely, T. Langenbacher, M. E. Michel-Beyerle, J. Jortner. Proc. Natl. Acad. Sci. USA 96, 11713 (1999).

5. P. T. Henderson, D. Jones, G. Hampikian, Y. Kan, G. B. Schuster. Proc. Natl. Acad. Sci. USA 96, 8353 (1999).

6. B. Giese. Acc. Chem. Res. 33, 631 (2000); G. B. Schuster. Acc. Chem. Res. 33, 253 (2000); C. Wan, T. Fiebig, O. Schiemann, J. K. Barton, A. Zewail. Proc. Natl. Acad. Sci. USA 97, 14053 (2000).

7. S. Steenken and S. V. Jovanovic. J. Am. Chem. Soc. 119, 617 (1997).

8. B. Giese and S. Wessely. Angew. Chem. Int. Ed. 39, 3490 (2000).

9. F. D. Lewis, T. Wu, Y. Zhang, R. L. Letsinger, S. R. Greenfield, M. R. Wasielewski. Science 277, 673 (1997).

10. B. Giese and M. Spichty. Chem. Phys. Chem. 1, 185 (2000).

11. F. D. Lewis, X. Liu, J. Liu, S. E. Miller, R. T. Hayes, M. R. Wasielewski. Nature 406, 51 (2000). 